BULLETIN Bulletin hispanique

HispaniQuE Université Michel de Montaigne Bordeaux

111-1 | 2009

Varia

\title{
Disciplinamiento social y reformismo moral
}

los orígenes de Don Juan

Andrés Moreno Mengíbar

\section{(2) OpenEdition}

Journals

Edición electrónica

URL: http://journals.openedition.org/bulletinhispanique/957

DOI: 10.4000/bulletinhispanique.957

ISSN: 1775-3821

Editor

Presses universitaires de Bordeaux

Edición impresa

Fecha de publicación: 1 junio 2009

Paginación: 265-280

ISBN: $978-2-86781-586-7$

ISSN: 0007-4640

Referencia electrónica

Andrés Moreno Mengíbar, « Disciplinamiento social y reformismo moral », Bulletin hispanique [En línea], 111-1 | 2009, Publicado el 01 junio 2012, consultado el 01 mayo 2019. URL : http://

journals.openedition.org/bulletinhispanique/957 ; DOI : 10.4000/bulletinhispanique.957

Tous droits réservés 


\title{
Disciplinamiento social y reformismo moral: los orígenes de Don Juan
}

\author{
Andrés Moreno Mengíbar \\ I.E.S. Santa \\ Aurelia - Sevilla
}

Jusqu'à aujourd'hui c'est dans la tradition littéraire qu'on a recherché les origines du personnage et du mythe de Don Juan; en revanche, c'est à peine si on a exploré les relations entre ce personnage et le retour à l'ordre moral et politique prôné par la ContreRéforme espagnole. Cet article met en évidence le lien entre l'auvre El burlador de Sevilla, son auteur supposé, Andrés de Claramonte, et le contexte historique que constitue l'action pastorale des jésuites sévillans aux alentours de 1610-1620.

Los origenes del personaje y del mito de Don Juan han sido hasta la fecha buscados en el terreno de las tradiciones literarias, pero no han sido apenas exploradas hasta el momento las relaciones entre este personaje y la campaña de reforma moral y politica de la Contrarreforma española. En este artículo se vincula la redacción de El burlador de Sevilla y a su posible autor, Andrés de Claramonte, con el entorno de la acción pastoral de los jesuitas sevillanos en torno a 1610-1620.

Until today, the origin of Don Juan's character and myth has traditionally been explored within the field of literary tradition. The links between Don Juan's character and the campaigns for moral reformation preached during the Spanish Counter-Reformation were nevertheless barely explored. This article tries to connect the original work, «El burlador de Sevilla", its supposed author, Andrés de Claramonte, with the historical context of the pastoral work Jesuits did in Seville, circa 1610-1620.

Mots-clés: Réformation morale - Jésuites - Andrés de Claramonte - Congrégations.

$B H i$, Tome 111, n 1 - juin 2009 - p. 265 à 280. 
Dartiendo del clásico análisis de Norbert Elias sobre el proceso civilizatorio en la Europa Moderna $^{1}$, la historiografía europea (especialmente la alemana y la italiana) de los años noventa inició un amplio programa de interrogación sobre las vías y las estrategias de penetración del poder en la sociedad del Antiguo Régimen. Conceptos como confesionalización o disciplinamiento social se han convertido en útiles instrumentos explicativos de los mecanismos de configuración e imposición de modelos de conducta por parte de las instancias de poder hegemónicas en la Edad Moderna: el Estado y la Iglesia (tanto católica como protestante) ${ }^{2}$. Ambas instancias confluyen estratégicamente en la necesidad de conformar un nuevo modelo de individuo, una nueva identidad del súbdito cristiano que pueda ser manejada e instrumentalizada en función de los intereses de poder. Se buscará implantar un estilo de comportamiento que, fundamentado en términos religiosos y morales, sea permeable a los requerimientos tanto de la autoridad religiosa como de la política. En este sentido, confesionalización y disciplinamiento social no son más que dos caras de un mismo proceso, el de la interacción entre la estructura eclesiástica y el estado Moderno con el objetivo de sustentar mutuamente el ejercicio del poder y del control social.

La historiografía sobre este particular ha desvelado los orígenes monásticos de los mecanismos de disciplinamiento social que comienzan a ser puestos en liza entre los fieles a partir de mediados del siglo $\mathrm{XVI}^{3}$. Se trataría de extrapolar y adaptar para los laicos las formas de autocontrol y de disciplina de los monjes, partiendo de la necesidad de superar la superficialidad de la vivencia religiosa de los fieles para alcanzar un modo de vida en su totalidad determinado por la experiencia religiosa y que se caracterizaría, a grandes rasgos, por la interiorización y la intensificación. Por una parte, hacer que los fieles, a quienes la Iglesia había prestado poca atención pastoral hasta la campaña post-tridentina, hagan de la

1. Norbert Elias, El proceso de civilización, México, Fondo de Cultura Económica, 1986.

2. La mejor recopilación de estudios a partir de estos conceptos historiográficos es VV.AA, Disciplina dell'anima, disciplina del corpo e disciplina della società tra Medioevo ed età Moderna, Annali dell'Istituto Storico Italiano-Germanico, 1994. Para el caso español es de obligada consulta Florencio Palomo, "Disciplina christiana'. Apuntes historiográficos en torno a la disciplina y el disciplinamiento social como categorías de la historiografía religiosa en la Alta Edad Moderna», Cuadernos de Historia Moderna 18 (1997), pp. 119-136.

3. Dilwyn Knox, «Disciplina: le origine monastiche e clericali del buon comportamento nell'Europa cattolica del Cinquecento al primo Seicento", en VV.AA., Disciplina dell'anima... Vid. también del mismo autor "Disciplina. Le origine monastiche e clericali della civiltà delle buone maniere in Europa", Annali dell'Istituto Storico Italo-Germanico in Trento, XVIII, 1992. 
experiencia religiosa una parte íntima de sí mismos y no un conjunto inconexo de prácticas externas. Por otro, impregnar de contenidos morales y espirituales todos y cada uno de los momentos de la existencia, desde los pensamientos más íntimos a las formas de sociabilidad. En este sentido, como bien han puesto de manifiesto los historiadores alemanes, no existen diferencias esenciales entre el ámbito católico y el entorno protestante, porque en ambos territorios se persiguen similares objetivos y se articulan las mismas estrategias tendentes a "la transformación planificada del comportamiento del hombre», en palabras de Reinhard ${ }^{4}$.

Centrándonos en el ámbito católico, los medios puestos en juego fueron de diversa índole, desde la propia fuerza represora del Estado y de la Iglesia (representada por el Santo Oficio como institución en la que confluían los intereses de ambas esferas de poder) a otras vías más cotidianas, de penetración paulatina y diaria, como la enseńanza, la catequesis (tanto la del púlpito como la de las misiones interiores ${ }^{5}$ ), la seducción por la palabra de la oratoria sagrada barroca y la confesión, cuestiones todas en las que, por existir ya una abundante bibliografía, no me voy a detener.

Sí nos interesa, a la hora de conectar el nacimiento de Don Juan con el proceso de disciplinamiento social, centrarnos en las estrategias de penetración cotidiana, en el proceso de intensificación y de interiorización de nuevos modelos de comportamiento. En estas cuestiones quien tomó la iniciativa y desarrolló los modelos que habrían de seguirse hasta finales del siglo XVIII fue la Compañía de Jesús. Desde sus momentos fundacionales quedó claro que la línea principal de la pastoral ignaciana era la de encauzar el curso de las pasiones humanas mediante una meditada y detallista línea de penetración en todos y cada uno de los momentos de la existencia de los fieles ${ }^{6}$. Se ha hecho mucho hincapié en los presupuestos cognitivos y en la introspección espiritual y moral que suponen los Ejercicios espirituales, pero no debe olvidarse que la práctica de los Ejercicios era entendida como el punto culminante de un proceso de disciplinamiento y de autocontrol $y$, por ello, estaba reservada a quienes alcanzaban un grado superior de

4. Wolfgang Reinhardt, «Disciplinamento sociale, confessionalizazione, modernizazione. Un discorso storiografico», en Disciplina dell'animanizazione. neale, tamiento del hombre»... p. 111.

5. Sobre esta cuestión resulta de imprescindible consulta Francisco Luis Rico Callado, Misiones populares en España entre el Barroco y la Ilustración, Instituto Alfonso el Magnánimo, Valencia, 2006.

6. Sobre la implantación de la Compañía en España y sus principales líneas de acción puede consultarse la reciente síntesis y la bibliografía citada en Teófanes Egido (coord.), Los jesuitas en España y en el mundo hispánico, Madrid, Marcial Pons, 2004. 
autoperfeccionamiento. A la hora de valorar el desarrollo y la eficacia de la pastoral jesuítica creo que puede resultar más interesante centrar la atención sobre las formas cotidianas de penetración en el tejido social.

Junto con las misiones interiores, el instrumento predilecto de la Compañía fue el de las congregaciones. Frente al carácter intenso pero esporádico de las misiones se situaba la acción cotidiana de las congregaciones. Éstas eran agrupaciones de fieles bajo la dirección espiritual de un padre de la Compañía. Su origen se sitúa en los colegios jesuitas, partiendo del Colegio Romano, donde un grupo selecto de estudiantes, al margen de sus tareas escolares, se reunían bajo la férula de un padre jesuita para, bajo alguna advocación particular (Anunciación de María, Espíritu Santo, Santísimo Sacramento), profundizar aún más en su formación moral y espiritual. Bajo el generalato del padre Aquaviva (1581-1615) se dio un enorme impulso a las congregaciones de colegiales, alcanzando del papado la bula Omnipotentis Dei (1584), por la cual todas las congregaciones pasaban a estar bajo el exclusivo control del General de la Compañía. Dos años más tarde, Sixto V autorizaba a extender el modelo congregacional más allá del ámbito de los colegios, admitiendo en su seno a clérigos y laicos de todo tipo. La iniciativa alcanzó una difusión inmediata, contabilizándose en 1615 más de un centenar de congregaciones en España ${ }^{7}$.

Tanto en los centros permanentes como en las localidades a las que se acudía en misiones, la estrategia primaria de los jesuitas era fundar congregaciones según el modelo creado en Italia. En función del volumen y tipo de población de cada lugar, estas congregaciones solían ser de varios tipos. En primer lugar, de clérigos a los que intentaban inculcar la espiritualidad ignaciana a través de la práctica habitual de los ejercicios espirituales y de frecuentes homilías, a la vez que intentaban integrarlos de forma más activa en la labor pastoral mediante la asistencia a hospitales y prisiones. Se perseguía, además, que estos clérigos sirvieran de correa de transmisión del nuevo paradigma espiritual más allá del alcance de la propia Compañía, pues cada uno de estos congregados debería repetir el esquema de actuación con los fieles en sus parroquias y demarcaciones mediante la creación de nuevas congregaciones que deberían ser supervisadas por la casa jesuita más cercana. De este modo, se ganarían más adeptos incondicionales para las «guerras» abiertas por los ignacianos: a favor del dogma de la Inmaculada y

7. No han sido hasta el momento estudiadas por extenso las congregaciones jesuíticas españolas. Una aproximación válida es la de Francisco Javier Martínez Naranjo, «Aproximación al estudio de las congregaciones de estudiantes en los colegios de la Compañía de Jesús durante la Edad Moderna», en Revista de Historia Moderna 20 (2002), 211-226. 
en contra de los carnavales (sintomáticamente denominados por los jesuitas Bacchanalia en sus informes anuales), del teatro y de las mancebías.

La segunda modalidad de congregaciones era la denominada «de caballeros», constituidas por los nobles y próceres locales que, además de detentar los principales poderes locales, podían servir de ejemplo para el resto de la sociedad. Con estas personas se ejercían homilías semanales, ejercicios espirituales, visitas a pobres y enfermos; se les instaba a perdonar públicamente a sus ofensores, poniendo fin a disputas locales inmemoriales; $y$, ante todo, se buscaba moldear una nueva figura del notable local, plenamente comprometido con la salvación de su alma y con el ejercicio de la caridad, para lo cual la Compañía fue especialmente insistente en que abandonasen formas de comportamiento anteriores que, como los duelos y enfrentamientos por puntos de honor, o el sostenimiento de amantes, servían de permanente escándalo a sus conciudadanos. Así, por ejemplo, la principal preocupación del Colegio de Jerez de la Frontera fue poner fin a los desmanes de la nobleza local, muy belicosa y amiga de bandos, de que se seguian continuos pleitos, rencillas y enemistades, desastres no pocos y muertes de muchos, panorama que cambiaría radicalmente a los pocos ańos del establecimiento de los jesuitas en la ciudad ${ }^{8}$.

Por último, no fue rara la existencia de un tercer tipo de congregaciones, encaminadas en este caso hacia la población más humilde a la que era más urgente cristianizar de verdad, es decir, hacerla abandonar una religiosidad superficial y teñida de supersticiones y de resabios mágicos. La escasa labor pastoral de la Iglesia en los siglos anteriores había creado verdaderas bolsas de paganismo real que habían sido terreno abonado para sectas y herejías. El ejemplo de la implantación rural del alumbradismo en la segunda mitad del siglo XVI convenció rápidamente a los jesuitas de la urgente necesidad de recristianizar a toda esa población, para lo cual el instrumento ideal fue el de las congregaciones populares. Jugando con el impulso de emulación, pronto consiguieron que en las zonas rurales prácticamente todos los campesinos se integraran en ellas para recibir una más intensa catequesis y atraerlos hacia los terrenos de combate espiritual predilectos de la Compañía. De esta manera, por citar algunos casos, la congregación de Marchena (Sevilla) contaba en 1614, al poco de fundarse, con 470 miembros ${ }^{9}$; por aquellas mismas fechas, la congregación de Écija (Sevilla)

8. Carta Annua de la Casa Profesa de Sevilla, 1602. Biblioteca Universitaria de Granada, caja C-15, fol. 267 e Historia del Colegio de la Compañia de Jesús en Xerez, ibidem, ff.167-168.

9. Annua Baeticae, 1614. Biblioteca Universitaria de Granada, caja C-15, fol. 328. 
agrupaba ya a trescientas personas ${ }^{10}$; la de Trigueros (Huelva), en el mismo año de su fundación (1610), atrajo a más de cuatrocientos integrantes ${ }^{11}$, la misma cifra de que se enorgullecía por entonces la congregación de Montilla (Córdoba), mientras que la de Úbeda (Jaén) congregaba habitualmente a trescientos miembros en $1612^{12}$. Especialmente espectacular fue el caso de Cazorla (Jaén), cuya congregación agrupaba en 1613 a setecientas personas de la localidad y de los pueblos vecinos ${ }^{13}$. Si a todas estas cifras les sumamos las de los alumnos de los colegios jesuíticos (ochocientos sólo en el de Córdoba), alumnos procedentes casi siempre de las mejores familias locales, podremos hacernos una idea de la enorme capacidad de penetración de ideas y de movilización de fuerzas sociales que la Compañía consiguió en Andalucía.

Dado el tema central de este artículo, voy a centrar el análisis en las congregaciones sevillanas, especialmente las que aglutinaban a las capas rectoras de la sociedad hispalense, ese entorno social e ideológico en el que se forja la redacción de Tan largo/Burlador ${ }^{14}$. Y ello por varios motivos: el primero y más importante porque sabemos que Andrés de Claramonte era miembro de la Congregación del Santísimo Sacramento ya en $1610^{15}$; y el segundo porque podemos afirmar que el entorno de los protectores sevillanos de Claramonte (la familia Ulloa, Gaspar de Saavedra, Diego de Arana) está directamente relacionado con el mundo de las congregaciones sevillanas y con sus particulares «batallas» por moralizar la vida de la ciudad. Lo que quiero poner sobre el tapete de la discusión es que Tan largo/Burlador nace en un contexto muy concreto de inquietud moral y política y que la obra puede ser entendida como el manifiesto escénico de la campaña de

10. Annua Baeticae, 1610. Biblioteca Universitaria de Granada, caja C-15, fol. 312.

11. Ibid.

12. Annua Baeticae, 1612. Biblioteca Universitaria de Granada, caja C-15, fol. 313.

13. Annua Baeticae, 1613. Biblioteca Universitaria de Granada, caja A-40, fol. 416v.

14. Aunque tradicionalmente se ha tenido a Tan largo me lo fáís como una refundición de El Burlador de Sevilla, ya Alfredo Rodríguez López Vázquez en su artículo «Una nota crítica a la prioridad del Tan largo me lo fiáis» (Bulletin of the Comediantes, Winter, 1988) había defendido la prioridad de Tan largo sobre El Burlador, basándose en criterios puramente textuales. Recientemente Ángel María García Gómez en su libro Vida teatral en Córdoba (1602-1694): autores de comedias, representantes y arrendadores, Tamesis Books, 2008, ha demostrado con datos notariales que la comedia Tan largo me lo fíís formaba parte del repertorio de la compañía de Jerónimo Sánchez en Córdoba en 1617, antes, por tanto, de la fecha comúnmente aceptada para la redacción de El Burlador de Sevilla.

15. Así se afirma en Luis Fernández Guerra y Orbe, Don Juan Ruiz de Alarcón y Mendoza. Real Academia Española, Imprenta de Rivadaneyra, 1871. 
reformación de la vida pública alentada por la Compañía de Jesús ya en los últimos ańos del reinado de Felipe III y en los primeros de Felipe IV.

Una de las estrategias más repetidas de la Compañía, al instalarse en una población, era la de atraerse a las más señaladas familias locales, especialmente a aquellas que ocupaban posiciones de poder importantes. Desde la década de los ochenta del siglo XVI, una vez avalados por disposiciones pontificias, en todas las ciudades con presencia jesuita se instauraba una congregación «de caballeros»:

El Marqués de Montes, asistente de Sevilla, y su cabeça en lo temporal, demás de acudir algunas vezes a esta casa a recebir los sacramentos en algunas otras ocasiones a dado muy buena muestras de la afición que tiene a la compañía (...). El regente que es el superior de la audiencia y muchos de sus oidores y alcaldes acuden a esta casa a frequentar los sacramentos y fuera dellos mucha gente principal ase ilustrado en gran manera en esta casa con las dos congregaciones que ay en ella, una de clérigos, y otra de cavalleros seglares ${ }^{16}$.

En el caso sevillano se siguió al pie de la letra la pauta marcada por la casa de Granada, donde los jesuitas habían tenido especial interés en atraerse a los principales cargos de la Real Chancillería por medio de la Congregación del Espíritu Santo, modelo de la congregación sevillana ${ }^{17}$. Como se ha expresado con anterioridad, una de las líneas de acción preferentes de la Compañía fue el modificar los hábitos de conducta de la nobleza. Ésta se movía tradicionalmente en función del honor y de la honra, lo que la llevaba a caer en actos violentos, duelos, desafíos y enemistades seculares que desequilibraban el orden de las ciudades por cuanto forzaban a importantes capas de la sociedad local a situarse en uno $\mathrm{u}$ otro bando. Los jesuitas dirigieron sus acciones pastorales hacia un nuevo modelo de cortesano, calculador, meditativo, que valora las consecuencias de sus acciones más allá del impulso colérico inicial y que se mueve, ante todo, a partir de parámetros cristianos en los que predominan valores como el perdón y la caridad. Es de lo que el teólogo Melchor Cano, feroz enemigo de la Compañía, se quejaba cuando decía que

16. Carta Annua de la Casa Profesa de Sevilla, 1601. Biblioteca Universitaria de Granada, caja C-15, fol. $265 \mathrm{v}$.

17. Sobre esta congregación vid. Miguel Luis López Muñoz, «La congregación del Espíritu Santo y otras congregaciones jesuíticas de la Granada Moderna», en Archivo Teológico Granadino 55 (1992), pp. 171-212. 
A los caballeros que toman entre manos, en lugar de hacerlos leones los hacen gallinas, y si los hallan gallinas, los hacen pollos, y si el Turco hubiera enviado a España hombres a posta para quitar los nervios y fuerzas de ella y hacernos los soldados mujeres y los caballeros mercaderes, no enviara otros más a su propósito... ${ }^{18}$.

Los desafíos y puntos de honor eran sustituidos por la pública reconciliación y el público perdón de las ofensas. Todo ello se realizaba a partir de un intenso proceso de interiorización de los valores de la humildad y de la caridad en el seno de las actividades de las congregaciones. No conocemos las normas internas de la congregación de caballeros de Sevilla, pero sí las de la granadina del Espíritu Santo, que fue el modelo de la hispalense. El preámbulo de sus reglas es ya de por sí bastante significativo:

El fin principal desta Congregación del Espíritu Santo (mirando siempre a la mayor gloria de nuestro señor) es que cada qual della tenga ante los ojos la importancia grande de su salvación, y como negocio grandísimo lo anteponga a todas las cosas del mundo, poniendo todos los medios necesarios para la execución dél, guardando exactamente la ley de nuestro Señor y ponderando la gravedad de un pecado mortal. Lo segundo, que cada uno procure el bien espiritual de sus próximos, procurando ganarlos para su Divina Magestad por todos los medios que la christiana prudencia pide, y viendo el mal estado de alguno, le exorte a la virtud con santas palabras y buen exemplo de su vida, y no pudiendo, suplique al Señor le dé verdadero conocimiento ${ }^{19}$.

Prácticamente, todos los momentos de la existencia de los congregantes están atravesados por ejercicios, devociones y disciplinas que buscan controlar el impulso de las pasiones. Se prescribe el uso frecuente de los sacramentos, con «un quarto de hora en acción de gracias por tan singular merced y beneficio». Cada día habría que tener un cuarto de hora de oración al levantarse. Avanzado el día, habría que rezar la tercera parte del rosario y oír misa, además de ofrecer una oración en acción de gracias al final de cada jornada, realizando un examen de conciencia de los actos del día, «trayendo a la memoria todos los defectos y discurriendo por las ocupaciones que han tenido, y pidiendo a nuestro Señor perdón dellos».

18. Citado por Teófanes Egido (coord.), Los jesuitas en España..., p. 16.

19. López Muñoz, «La congregación del Espíritu Santo...», p. 170. 
Ello se debería complementar diariamente con una lectura «en un libro espiritual». Semanalmente se debería tener "algún exercicio de penitencia» según lo ordenase el confesor o padre de la congregación. También una vez por semana habría que asistir a la predicación en alguna iglesia, "procurando traer consigo otros para que por este camino se aficionen a la virtud». Todo congregante debería ser ejemplo de comportamiento ante los demás, especialmente en "la modestia de las palabras y obras», desterrando los juramentos, las palabras ofensivas y la asistencia a comedias y juegos. Como camino para desprenderse del orgullo de clase y de la vanidad de los cargos, era preceptivo el ejercicio de la caridad con los pobres y enfermos de los hospitales y con los presos de las cárceles. Finalmente, deberían tener especial interés en «hazer amistades entre los discordes», evitando así las disputas entre familias y la violencia urbana.

Una de las funciones latentes de este tipo de agrupaciones era el de crear nuevas estructuras de sociabilidad basada en el sentido sacralizado de la existencia y que fragmentasen los lazos de solidaridad de clase que, especialmente en el caso de la nobleza, eran la condición de posibilidad de formas de comportamiento violento, inmoral y contrario al nuevo modelo de sociabilidad cristiana interclasista propuesto por los jesuitas. De ahí que en estas congregaciones se fomentase el sentido de solidaridad entre sus miembros, la ayuda mutua y el consejo fraterno a través de reuniones que, en algunos casos, podían ser diarias. Éste era el caso de la congregación del Santísimo Sacramento a la que pertenecía Andrés de Claramonte. Un cronista de la Compañía relata así el desarrollo de las reuniones:

El tiempo señalado era la señal de las Ave Marías, cuando es ordinario alzar de obra los oficiales. A el son de esta campana se juntavan como forma de congregación. Leía uno un buen rato en un libro espiritual, de donde se tomaban para la meditación unos dos o tres puntos. Seguíase a éste el ejercicio de la disciplina tres días en la semana; en adviento y cuaresma todos. Las más de las veces el Hermano Mateo les hacía una breve pero fervorosa exortación con que se despedían devotos y consolados $^{20}$.

La Compañía utilizó sistemáticamente a sus congregaciones para sus particulares batallas por la moralización pública y por la imposición de una

20. Juan de Santibáńez, Historia de la Provincia de Andalucía de la Compañía de Jesús. Manuscrito en Biblioteca de la Facultad de Teología de Granada, $2^{\circ}$ parte, libro 3, cap. 29, p. 181. 
serie de cultos considerados prioritarios. Es el caso de la campaña en pro de la definición del dogma de la Inmaculada Concepción de María y que, en el caso sevillano, adquirió aires de fuerte virulencia (y no sólo teológica) en los años 1613-1617. Los jesuitas no dudaron en hacer uso de sus congregantes como instrumentos de presión social, sacándolos a la calle para cantar coplas en defensa de la pureza de María y en vituperio de la orden dominica, que se negaba a reconocer dicho dogma. La disputa inmaculista llegó a niveles de violencia callejera contra los dominicos en algunos casos, tal y como denuncia el provincial de la orden de los predicadores en un interesante documento de mayo de 1615 y en el que se acusa a la Compañía de haber

\section{(...) instigado a los congregados de su casa y a gente baja y officiales para que nos den cantaletas de noche a nuestros conventos, y componiendo coplas y dándolas a los estudiantes que las canten... ${ }^{21}$.}

Creo que es en este contexto en el que hay que situar la redacción por parte de Claramonte de su Fracmento a la Puríssima Concepción en el año 1613, dedicado precisamente a la familia Ulloa, cuyo cabeza, Fernando de Ulloa, ocupaba un puesto relevante en el concejo sevillano. Otra posible pista para afianzar la relación de Claramonte con los jesuitas la podemos encontrar en la Loa sacramental [y] en metáfora de las iglesia[s d]e Sevilla, representada por el comediante Diego de Ávila en la fiestas sevillanas del Corpus de 1620. En el recorrido simbólico-topográfico que Cristo realiza por los templos sevillanos buscando acogida, refiere que [só]lo halla en la Compañial[u]n Juan que le favoresca ${ }^{22}$, lo cual puede ser entendido, a mi parecer, como muestra del fervor de Claramonte hacia la Compañía de Jesús.

Las relaciones de Claramonte con los jesuitas sevillanos y con su acción pastoral y moral se pueden ampliar por medio de la relación de protección que el dramaturgo murciano mantenía con importantes cargos de la Audiencia sevillana, como Gaspar de Saavedra y Diego de Arana (lo que, por otra parte, explicaría la familiaridad de Claramonte con la terminología jurídica que tan a menudo aparece en sus textos), pues ya he señalado más arriba que, siguiendo el modelo granadino con la Real Chancillería, los jesuitas sevillanos tuvieron especial interés en atraerse el favor y el fervor

21. Biblioteca Universitaria de Sevilla, 333/166, ff. 47-48.

22. Mercedes de los Reyes Peńa, «La Sevilla de Cervantes a través de una loa de Andrés de Claramonte», en Alfredo Hermegildo, César Oliva y Catherine Poupeney, Cervantes y la puesta en escena de la sociedad de su tiempo. Actas del Coloquio de Montreal, 1997, Murcia, Universidad de Murcia, 1999, p. 215. 
de los puestos superiores de la Audiencia, una institución que iba más allá de las competencias judiciales y que ejercía, en realidad, una instancia de gobierno de la vida urbana paralela (y a menudo en competencia) a la del Ayuntamiento. Ante la resistencia municipal a algunas de sus iniciativas (como el cierre de la mancebía, por ejemplo ${ }^{23}$ ), la Compañía movilizaba sus influencias en la Audiencia hasta conseguir neutralizar los obstáculos concejiles.

Y, por último, a modo de eslabón final que une el círculo JesuitasClaramonte-Ulloa-Don Juan, tenemos a la figura de Doña Magdalena de Ulloa, protectora de la Compañía y generosa en la dotación económica de colegios en Villagarcía de Campos, Oviedo y Santander, llamada por el jesuita Juan de Villafañe ${ }^{24}$ "La limosnera de Dios». Es el único caso de una mujer admitida casi como igual por los jesuitas y cuyo ejemplo sin duda que debió influir en la relación de la Compañía con los Ulloa sevillanos.

Quisiera a continuación, una vez asentados los datos que permiten relacionar a Claramonte con el contexto moral y político articulado por la Compañía de Jesús en la Sevilla de 1600-1615, establecer, aun de forma esquemática, una serie de cuestiones en las que Tan largo/Burlador me parece reflejan algunas de las principales inquietudes y líneas de actuación del programa de reformas morales y políticas alentado por los jesuitas, no ya a nivel local, sino a nivel de toda la Monarquía.

Como se ha señalado con anterioridad, las congregaciones de nobles y caballeros perseguían modificar los hábitos de conducta de la aristocracia. En concreto fueron objeto de especial atención los comportamientos derivados del ethos del honor, la violencia incontenible y la cólera caprichosa que tanto caracterizaban a los nobles españoles de la época. El contramodelo perseguido mediante los mecanismos ya explicitados era el del noble que asume su posición social como modelo para las clases plebeyas, por una parte, y por otra como fino y astuto cortesano que ahora debe ganar prestigio y poder no mediante la fuerza, como en la época feudal, sino mediante la astucia, el autocontrol, el disimulo de las emociones y las redes de solidaridad

23. Para la campaña jesuítica contra las mancebías, vid. Francisco Vázquez García y Andrés Moreno Mengíbar, Poder y Prostitución en Sevilla, Sevilla, Publicaciones de la Universidad de Sevilla, 1998 (2a edición), Vol. 1, pp. 122-165 y de los mismos autores Historia de la prostitución en Andalucia, Sevilla, Fundación José Manuel Lara, 2004, pp. 75-117.

24. Juan de Villafañe (S.J.), La limosnera de Dios: relación histórica de la vida, y virtudes de la excelentisima Señora doña Magdalena de Ulloa..., Salamanca, en la Imprenta de Francisco García Onorato, s.a. Sobre este personaje puede verse Félix Rodríguez Herreras (coord.), Doña Magdalena de Ulloa, mujer de Luis Quixada, 1598-1998. Valladolid, Diputación Provincial, 1998. 
interclánicas. Inteligencia frente a impulsos primarios. Razón frente a Pasión. Éste es el nuevo paradigma del cortesano que alcanzará su mejor definición en los escritos de un jesuita como Gracián y del que la figura de Don Juan parece ser la figura invertida.

Don Juan obedece en todos sus actos al viejo modelo pulsional que, a las alturas de los años en que se gesta y redacta el drama, los propios moralistas de la Compañía están en proceso de redefinir ${ }^{25}$. Dicho modelo en proceso de sustitución y forjado en los tiempos de los Primeros Padres del cristianismo sostenía la irrefrenabilidad de los movimientos de la carne, una carne rebelde a los dictados de la razón (trasunto de la rebeldía del Hombre contra Dios), que arrastra tras de sí a la voluntad y que sólo podía ser morigerada y reprimida mediante las penitencias y disciplinas. En función de la desconexión entre Razón y Pasión, la moral medieval y renacentista juzgaba, en cuestiones relacionadas con los pecados de la carne, más los actos que los pensamientos, estableciendo una tarificación de la gravedad de los pecados de lujuria que juzgaba de forma prioritaria la gravedad de las consecuencias externas de los $\operatorname{actos}^{26}$. Así, incluso considerando el carácter mortal de los pecados de lujuria (para los que no había parvedad de materia), la escala inferior la ocupaba la simple fornicación (las relaciones sexuales entre solteros) y la superior las relaciones sacrílegas y demoníacas. Para los moralistas de la Compañía, en cambio, no podía seguir manteniéndose la desconexión entre Razón y Pasión, dado que el hombre se define estrictamente por su racionalidad. Es en los pensamientos y en las intenciones donde anida el Mal y de donde proceden los actos depravados y los excesos carnales. Lo que de verdad debe interesar al confesor no es únicamente el examen de los actos del penitente, sino especialmente los pensamientos que permiten descubrir un alma pecadora. No se juzgan actos aislados, sino formas de pensamiento, estados del alma regulados por la razón y que pueden ser alterados por cualquier pequeña infracción sin aparente trascendencia. La mera fornicación, aún con prostitutas, no aplaca a una carne rebelde (justificación doctrinal tradicional de las mancebías): enciende y multiplica las infracciones, desata una escalada de perversiones que puede llevar hasta los extremos más infernales.

Las pautas de comportamiento de Don Juan se conforman con exactitud con el paradigma pulsional que los jesuitas están desterrando a principios del siglo XVII. En este sentido estamos de acuerdo con Starobinski cuando sostiene que

25. Sobre esta cuestión puede consultarse Francisco Vázquez García y Andrés Moreno Mengíbar, Sexo y Razón. Una genealogía de la moral sexual en España (siglos XVI-XX), Madrid, Akal, 1997, pp. 297-301.

26. Desarrollamos por extenso esta cuestión en ibidem, pp. 49-75. 
El mito de Don Juan se constituye en un momento de la Historia europea en el que el motivo de la inconstancia del corazón humano y el de sus concupiscencias -sentir, saber, dominar (libido sentiendi, libido sciendi, libido dominandi)preocupan especialmente a los moralistas. ¿Qué será del hombre sin la gracia? El pensamiento teológico responde que se verá sometido a sus apetitos y al amor de sí, indiferente a toda autoridad que contradiga sus placeres ${ }^{27}$.

Para la pastoral jesuítica, la Gracia divina opera iluminando la razón humana para que sea ella quien refrene el impulso de las pasiones y de las emociones. Don Juan, por el contrario, es pura acción, pura desmesura en el desbocamiento de sus impulsos, completa anulación de las potencias intelectivas en beneficio de las pasiones animales. "Viento soy»: así se identifica ante Isabela, aludiendo al carácter irrefrenable del viento como trasunto de sus pasiones libidinosas, equiparando viento con lujuria en diversos pasajes de Tan largo/Burlador. Él es consciente de su personalidad desbocada: «Si el burlar/es hábito antiguo mío,/¿qué me preguntas, sabiendo/mi condición?» El reconocer su condición, su personalidad trasgresora sin poner remedio ni pedir consejo ni, aún más, sentirse orgulloso de ello, le hace aún más culpable a la vista de la teología moral cristiana, que lo caracterizaría no sólo de pecador, sino de réprobo.

Con su desenfrenado comportamiento, Don Juan no sólo pone en entredicho el modelo cortesano, sino que también destruye el valor de la nobleza como ejemplo y guía de la sociedad del Antiguo Régimen. Los engaños del Tenorio afectan al mundo aristocrático reflejado en los personajes de Isabela, Doña Ana, el Duque Octavio y el Marqués de la Mota, sí, pero también al estado llano representado por Tisbea, Aminta y Batricio. En este sentido, los engaños donjuanescos ponen en peligro el lugar social de la nobleza y amenaza con subvertir el orden si los campesinos y plebeyos se rebelan contra sus señores, una situación que estaba latente en la España del momento y que estallaría poco después en un amplio movimiento de rebeldía campesina y antiseñorial. Son los años que Stone calificó como de "crisis de la aristocracia», un concepto acuñado para el caso inglés y aplicado para el español por autores como Iago o Yun ${ }^{28}$.

27. Jean Starobinski, Les Enchanteresses. Ed. du Seuil, 2005, pág. 88, la traducción es nuestra.

28. Lawrence Stone, La crisis de la aristocracia. Madrid, Revista de Occidente, 1976. Charles Iago, "La crisis de la aristocracia en la Castilla del siglo XVII», en Poder y sociedad en la España de los Austrias, Barcelona, Crítica, 1982. Bartolomé Yun Casalilla, «La crisis de la aristocracia en España e Inglaterra. Una visión comparativa», en VV. AA. Las crisis en la 
Esta última consideración me lleva a plantear también una dimensión política en la gestación de Tan largo/Burlador. El programa de reformación (por utilizar un término de la época) inspirado por la pastoral ignaciana tenía un doble perfil, dos caras de la misma moneda. Por una parte, como ya hemos señalado, la transformación de los patrones de moralidad y la redefinición de las identidades cristianas. Esta construcción de un nuevo modelo de fiel cristiano no alcanzaría, en la visión de los jesuitas, sus objetivos (crear una auténtica República Cristiana) si el marco institucional y los instrumentos de gobierno no se guiaban bajo los mismos principios de moralidad. A este respecto, la Compañía de Jesús se adhirió a una campaña ya en marcha que denunciaba el estado de corrupción política y de descrédito de las más altas instituciones provocado por la dejadez de sus funciones de Felipe III y por el poder personal y prevaricador de su privado, el Duque de Lerma. Desde 1615 arrecian las publicaciones que exigen, en función de parámetros estrictamente religiosos, el fin del nepotismo, del saqueo del erario público y de las arbitrariedades, pidiendo al Rey que asuma su papel y guíe a su pueblo hacia el buen gobierno ${ }^{29}$. La Compañía de Jesús jugaría sus bazas apostando por el entorno de ZúńigaOlivares y del joven príncipe Felipe. Cuando éste suba al trono en 1621, los puestos de confesor del privado y de los hermanos del Rey serán copados por jesuitas. Es más, influyentes miembros de la Compañía como Jerónimo de Florencia o Hernando de Salazar impulsarán la creación de la Junta de Reformación de 1621 y de la Junta Grande de reformación al año siguiente, órganos consultivos desde los que se intentó llevar a la práctica legislativa y ejecutiva un modelo de gobierno teocrático y moralizante. El programa reformista se trasladó también a las Cortes de Castilla, que ya en 1617 están solicitando de la Corona que se aborde un plan de saneamiento no sólo económico, sino (lo que es más importante) sobre todo moral que lleve la limpieza, la transparencia y la decencia a la vida pública ${ }^{30}$. Habría que señalar que en el movimiento de resistencia contra los validos articulado desde las ciudades con representación en las Cortes castellanas, podemos encontrar como a uno de sus promotores al procurador sevillano Juan de Vargas. Miembro del concejo sevillano, Vargas colaboró estrechamente con Fernando de Ulloa en la reforma de las ordenanzas de la mancebía hispalense

Historia, Salamanca, Universidad de Salamanca, 1995.

29. Sobre esta campaña vid. Antonio Feros, El Duque de Lerma. Realeza y privanza en la España de Felipe III. Marcial Pons, Madrid, 2002, pp. 422-426.

30. Esencial para esta cuestión es el análisis de John H. Eliot, El Conde-Duque de Olivares. Mondadori, Barcelona, 1998, pp. 114-159. 
en 1619-1620, lo que hace presumir una sintonía entre ambos por acabar con el despotismo y la inmoralidad de la vida pública española.

Si bien la crítica contra los validos es mucho más evidente en La Estrella de Sevilla (como lo es en otras obras nacidas en estos momentos cruciales, como Deste agua no beberé, El ataúd para el vivo y tálamo para el muerto o La niña de plata), en la que encontramos a un Ulloa defendiendo la legalidad contra los embates del privado don Arias y del rey Sancho IV, en Tan largo/Burlador resulta también clara esta intencionalidad, si bien no se erige en el núcleo articulador del drama. Para cualquier espectador de la época resultaría evidente que, en buena parte, Don Juan puede perpetrar todos sus desmanes porque se aprovecha tanto de la lenidad y la falta de energía política de Alfonso XI como de la protección del privado del rey y padre de Don Juan. Nada más comenzar el drama sabemos que Don Juan se encuentra en Nápoles gozando de la protección del Rey y del embajador castellano, su propio tío, pues ha tenido que salir de Castilla a causa de una de sus fechorías. Cuando en Nápoles reincide y burla a Isabela, de nuevo el favor real le facilita la huida y el regreso a Castilla, donde de nuevo el rey Alfonso será permisivo con los desórdenes del burlador a causa de la influencia negativa de su privado. De hecho, la justicia real no puede en ningún momento poner fin a los crímenes y deshonras de Don Juan y tiene que ser la justicia divina quien reinstaure el orden y el equilibrio. « $¿$ Esto mis privados hacen?», se lamenta inútilmente Alfonso XI al final de la comedia, siendo consciente de la dejadez de su propia conducta y del excesivo margen de actuación que ha concedido a su valido.

La crítica hacia la falta de autoridad no sólo se establece en Tan largo/ Burlador hacia la figura regia, sino que se traslada también hacia la responsabilidad que los padres tienen hacia sus hijos. Para cualquier mediano conocedor del teatro y de la novela cortesana de la época será familiar la existencia de numerosos personajes que cometen los mayores errores, desmanes, crímenes y transgresiones como consecuencia de una mala educación derivada de la dejación que los padres en sus deberes como formadores de sus hijos ${ }^{31}$. Precisamente la conciencia de esta realidad entre las clases superiores de la sociedad, que tradicionalmente daban poca importancia a la educación de su prole, llevó a la Compañía de Jesús a especializarse en la formación de los jóvenes, creando en todas las ciudades en las que estaba implantada colegios gratuitos de lo que hoy llamaríamos

31. He intentado desarrollar esta cuestión para el caso femenino en «Ver y Ser Vista: el modelo familiar de la educación femenina en el Siglo de Oro», en Jean-Louis Guereña (dir.), Famille et éducation en Espagne et en Amérique Latine, Universidad François Rabelais, Tours, 2002. 
enseñanza secundaria. El colegio sevillano y su pedagogía son alabados por Cervantes en el Coloquio de los perros. En este sentido, Don Juan responde perfectamente al modelo del hijo de buena familia malcriado y gamberro. Junto con el Marqués de la Mota y don Pedro de Esquivel dan nombre a esa "gente de barrio» mencionada por Cervantes en El celoso extremeño, jóvenes ricos que se dedicaban al engańo, las trifulcas, los desafíos y a dar "perros muertos» a las prostitutas de la mancebía. Que no se trata únicamente de una figura literaria nos lo atestigua un interesante documento fechado el 26 de diciembre de 1583 y por el cual el Asistente de Sevilla informa al Consejo de Castilla de que

La noche de Navidad saliendo yo de sant leandre de echar de la yglesia muchos hombres que perturbavan la devoción de las mugeres con palabras y actos desonestos, quedó atrás un criado mío con una linterna encendida y acaso topó a la puerta de la yglesia con don Juan viçentelo y vicente Corço que llevavan ciertas mugerzillas de maltrato y por sola ocasión de haverles dado la lumbre en la cara trataron mal de palabra a mi criado y don Juan le dio de espaldarazos y el vicente una cuchillada en la cabeça. Acudí al ruydo y llevé preso al vicente y le tuve en un çepo aquella noche y parte del día siguiente y a la mañana savida la culpa de don Juan, le embié preso a las ataraçanas. V. m. conosca la inquietud destos moços, de cuyo mal proceder está harto sentido y lastimado el viejo y entiendo que se le haría buena obra en apretallos y tenellos assí algunos días para que escarmentasen y enmendasen la licenciosa vida que hazen ${ }^{32}$.

El documento es más revelador de lo que aparenta, porque ese don Juan Vicentelo mencionado es el abuelo de Miguel de Mañara, en quien en algún momento se ha querido ver el modelo de don Juan Tenorio. Si bien es imposible que Mañara, nacido en 1627, fuese el origen del personaje, sí sería posible ver en su abuelo, otro don Juan al parecer famoso en la Sevilla cervantina por sus calaveradas, a una posible figura a la que Claramonte recurriese a la hora de diseńar el personaje de su comedia. Sea como fuere, la verdad es que el personaje funciona a la perfección como advertencia de las consecuencias que deberían arrostrar aquellos padres que se desentendiesen de la formación de sus vástagos, tal y como también aparecía, aquí de forma más evidente, en el teatro escolar de los jesuitas.

32. Archivo General de Simancas. Guerra Antigua, legajo 132, nº 36. 